\title{
Utilização de diferentes tipos de estaca na produção de mudas do porta-enxerto de videira, CV. IAC 572 'Jales'
}

\author{
Effects of different kinds of cuttings in the scion \\ production grapevine rootstocks, \\ CV. IAC 572 'Jales'
}

\section{Patrícia Coelho de Souza Leão ${ }^{1}$}

\section{RESUMO}

Este estudo teve como objetivo avaliar diferentes tipos de estacas sobre o enraizamento, brotação e desenvolvimento de mudas do porta-enxerto de videira cv. IAC 572. O experimento foi conduzido no viveiro do Serviço de Negócios Tecnológicos (SNT), da Embrapa, em Petrolina-PE, utilizando-se delineamento experimental inteiramente casualizado com cinco tratamentos e quatro repetições, sendo vinte e cinco estacas por parcela. Os tratamentos foram: estacas lenhosas com três gemas, estacas lenhosas com duas gemas, estacas lenhosas com uma gema, estacas herbáceas com duas gemas e estacas herbáceas com uma gema. Aos 60 dias após o plantio, as estacas lenhosas com três gemas apresentaram os maiores percentuais de enraizamento (99\%) e brotação (99\%) e melhor desenvolvimento da parte aérea e do sistema radicular, entretanto, não diferiu dos valores obtidos para enraizamento e brotação pelo emprego de estacas lenhosas com uma gema.

Palavras-chave: Vitis spp., uva, propagação, enraizamento, brotação.

\section{ABSTRACT}

This study aimed at evaluating different kinds of cutting with variable bud number on rooting, budding percentage and development of grapes scions stock $\mathrm{cv}$. IAC
572. A trial was carried out in a nursery at Embrapa in Petrolina, Brazil, in a randomized design, with four replications and five treatments, with 25 cuttings each plot. The treatments are the following: 1) Three bud ligneous cutting; 2) Two bud ligneous cutting; 3) One bud ligneous cutting; 4)Two bud herbaceous cutting and 5) One bud herbaceous cutting. At 60 days after planting, three bud ligneous cutting presented the greatest percentages of rooting (99\%) and budding (99\%) and best development of shoots and roots. However, these results are not significantly different $(p>0.5)$ to the values obtained to rooting and budding using one bud ligneous cutting.

Key words: Vitis ssp., grape, propagation, rooting, budding.

A utilização de mudas certificadas de elevada qualidade constitui um dos fatores de maior importância no estabelecimento de vinhedos uniformes, sadios e produtivos. Mudas com bom desenvolvimento da parte aérea e do sistema radicular terão maiores chances de adaptação às condições de campo, resultando em plantas mais vigorosas.

Em viticultura, utiliza-se a propagação vegetativa das variedades cultivadas através de

'Engenheiro Agrônomo, MSc., Embrapa Semi-Árido, CP 23, BR 428, Km 152, 56000-970, Petrolina, PE. E-mail: patricia@cpatsa.embrapa.br. Autor para correspondência. 
enxertia, que pode ser realizada em viveiro ou em porta-enxertos estabelecidos no local definitivo. A propagação dos porta-enxertos, por sua vez, é realizada através de estaquia. ALBUQUERQUE \& ALBUQUERQUE (1981) recomendam a utilização de estacas com 20 a $30 \mathrm{~cm}$ de comprimento ou três gemas. Segundo HARTMANN \& KESTER (1968) podem ser considerados como fatores primários para o enraizamento e brotação das estacas, a seleção adequada do material vegetativo, o substrato enraizante, a água disponível e condições apropriadas de luz, aeração, temperatura e umidade.

Medidas que aumentem a capacidade de fornecimento de estacas pelas plantas matrizes são de grande importância, pois, nos últimos anos, a disponibilidade de material vegetativo sadio e de boa qualidade tem sido menor que a demanda, em virtude da expansão das áreas cultivadas. De acordo com WINKLER et al. (1974), a grande vantagem de utilização de estacas herbáceas na produção de mudas de videira é a possibilidade de formação de um grande número de estacas a partir de uma única planta matriz. Isto pode ser obtido, também, utilizando-se estacas com menor comprimento ou menor número de gemas.

Este estudo teve como objetivo avaliar os efeitos do emprego de estacas herbáceas e lenhosas com número de gemas variável sobre o enraizamento, brotação e desenvolvimento das brotações e sistema radicular de mudas de porta-enxerto de videira cv. IAC 572 'Jales'.

O trabalho foi conduzido no viveiro de mudas do Serviço de Negócios Tecnológicos (SNT) da Embrapa, em Petrolina, PE. O viveiro onde foi conduzido o experimento apresentava-se coberto com tela de sombrite com $50 \%$ de sombreamento e irrigação por microaspersão. $\mathrm{O}$ delineamento estatístico foi inteiramente casualizado, com cinco tratamentos e quatro repetições. Cada parcela foi composta por vinte e cinco estacas do porta-enxerto IAC 572 'Jales'. Foram utilizados os seguintes tratamentos: 1- estaca lenhosa com três gemas; 2- estaca lenhosa com duas gemas; 3- estaca lenhosa com uma gema; 4- estaca herbácea com duas gemas e 5- estaca herbácea com uma gema.

Para o tratamento estacas lenhosas com três gemas, as estacas foram preparadas com $25 \mathrm{~cm}$ de comprimento e aproximadamente $8 \mathrm{~mm}$ de diâmetro, e para os demais tratamentos utilizou-se um comprimento padrão de $9 \mathrm{~cm}$ e diâmetro de 4 a $5 \mathrm{~mm}$. As estacas foram plantadas em saquinhos de polietileno contendo solo como substrato. Os tratos culturais e fitossanitários foram realizados de acordo com a necessidade.

Foram retiradas as estacas aos 60 dias após o plantio para avaliação da percentagem de enraizamento e brotação. Separou-se uma amostra de cinco estacas enraizadas por parcela para avaliar o comprimento das raízes, área foliar das brotações e peso da matéria seca das brotações e raízes. Para estimativa do comprimento de raízes, utilizou-se o método de intersecção de linhas descrito por TENNANT (1975). Para análise estatística, os dados percentuais foram transformados em raiz quadrada de arcsenx, onde " $x$ " representou o valor médio obtido, sendo as médias de todos os tratamentos comparadas pelo teste de Tukey a $5 \%$ de probabilidade.

O tratamento estacas lenhosas com três gemas apresentou, de acordo com a Tabela 1,99\% de enraizamento e não diferiu significativamente dos tratamentos estacas lenhosas com duas e com uma gema, que apresentaram respectivamente, $74 \%$ e $88 \%$ de estacas enraizadas. O percentual de enraizamento para estacas herbáceas foi inferior aos tratamentos estacas lenhosas e variou de 29\% para estacas herbáceas com duas gemas e $37 \%$ para estacas herbáceas com uma gema. Estes resultados são semelhantes àqueles encontrados por POMMER et al. (1996) que obtiveram $100 \%$ de enraizamento em estacas semi-lenhosas na cv. IAC 572 e ALVARENGA \& FORTES (1975) que encontraram $97,2 \%$ de enraizamento em estacas lenhosas desta mesma cultivar em condições de campo. Os resultados obtidos neste trabalho também são semelhantes àqueles observados por TERRA et al. (1988) que alcançaram 90\% em estacas lenhosas na cv. IAC 766 e MELO et al. (1996) que obtiveram 50\% de enraizamento em estacas herbáceas com duas gemas na cv. IAC 572 sob condições de nebulização intermitente.

A brotação das estacas apresentou comportamento similar ao enraizamento (Tabela 1), isto é, obteve-se $99 \%$ de brotação em estacas lenhosas com diferença significativa para estacas lenhosas com duas gemas e estacas herbáceas, estas, por sua vez, apresentaram porcentuais de brotação inferiores, ou seja, $28 \%$ para estacas herbáceas com uma gema e $37 \%$ para estacas herbáceas com duas gemas. Estes resultados demonstram que o estado de lignificação da estaca tem maior influência sobre o número de estacas enraizadas e brotadas que o comprimento ou o número de gemas da estaca. Entretanto, segundo WINKLER et al. (1974), o enraizamento e brotação das estacas herbáceas podem atingir facilmente $100 \%$ quando se utiliza sistema de irrigação por nebulização intermitente, pois os baixos porcentuais de enraizamento e brotação ocorrem pela elevada desidratação dos tecidos nas estacas herbáceas.

A área foliar das brotações para o tratamento estacas lenhosas com três gemas foi $456,46 \mathrm{~cm}^{2}$ (Ta- 
Tabela 1 - Valores médios obtidos para percentuais de enraizamento e brotação, área foliar, peso da matéria seca das brotações e raízes e comprimento do sistema radicular de mudas do porta-enxerto cv. IAC 572, utilizando-se diferentes tipos de estaca. Petrolina, 1996. ${ }^{1}$

\begin{tabular}{|c|c|c|c|c|c|c|c|c|c|c|c|c|}
\hline \multirow[b]{2}{*}{ Estaca lenhosa 3 gemas } & \multicolumn{2}{|c|}{$\begin{array}{c}\text { Enraizamento } \\
(\%)\end{array}$} & \multicolumn{2}{|c|}{$\begin{array}{c}\text { Brotação } \\
(\%)\end{array}$} & \multicolumn{2}{|c|}{$\begin{array}{l}\text { Área foliar } \\
\left(\mathrm{cm}^{2}\right)\end{array}$} & \multicolumn{2}{|c|}{$\begin{array}{c}\text { Peso seco de } \\
\text { brotações (mg) }\end{array}$} & \multicolumn{2}{|c|}{$\begin{array}{l}\text { Peso seco de } \\
\text { raízes }(\mathrm{mg})\end{array}$} & \multicolumn{2}{|c|}{$\begin{array}{l}\text { Comprimento de } \\
\text { raízes }(\mathrm{cm})\end{array}$} \\
\hline & 99 & $\mathrm{a}$ & 99 & $\mathrm{a}$ & 456,5 & $\mathrm{a}$ & $1.700,0$ & $\mathrm{a}$ & 972,5 & $\mathrm{a}$ & 358,3 & $\mathrm{a}$ \\
\hline Estaca lenhosa 2 gemas & 74 & a & 74 & $\mathrm{~b}$ & 86,2 & $\mathrm{~b}$ & 357,5 & $\mathrm{~b}$ & 507,5 & $\mathrm{ab}$ & 129,5 & $\mathrm{~b}$ \\
\hline Estaca lenhosa 1 gema & 88 & $\mathrm{a}$ & 92 & $\mathrm{ab}$ & 114,5 & $\mathrm{~b}$ & 390,0 & $\mathrm{~b}$ & 460,0 & $\mathrm{~b}$ & 239,7 & $a b$ \\
\hline Estaca herbácea 2 gemas & 29 & $\mathrm{~b}$ & 28 & $\mathrm{c}$ & 34,4 & $\mathrm{~b}$ & 155,0 & $\mathrm{~b}$ & 175,0 & $\mathrm{~b}$ & 113,4 & $\mathrm{~b}$ \\
\hline Estaca herbácea 1 gema & 37 & $\mathrm{~b}$ & 37 & $\mathrm{c}$ & 45,6 & $\mathrm{~b}$ & 202,5 & $\mathrm{~b}$ & 202,5 & $\mathrm{~b}$ & 102,4 & $\mathrm{~b}$ \\
\hline C.V. $(\%)$ & \multicolumn{2}{|c|}{19,9} & \multicolumn{2}{|c|}{16,5} & \multicolumn{2}{|c|}{28,6} & \multicolumn{2}{|l|}{25,8} & \multicolumn{2}{|c|}{45,5} & \multicolumn{2}{|c|}{37,0} \\
\hline
\end{tabular}

${ }^{1}$ Médias seguidas pela mesma letra não diferem entre si pelo teste de Tukey a $5 \%$ de probabilidade.

bela 1) com diferença significativa para os demais tratamentos. Pode-se observar uma superioridade das estacas lenhosas sobre as estacas herbáceas como também das estacas com uma gema sobre as estacas com duas gemas, apesar dessas diferenças não serem significativas pelo teste de Tukey a $5 \%$ de probabilidade. O peso seco das brotações apresentou comportamento semelhante, destacando-se o tratamento estacas lenhosas com três gemas com 1.700mg. Manteve-se a tendência de superioridade das estacas lenhosas e das estacas com uma gema sobre as estacas com duas gemas.

As estacas lenhosas com três gemas também apresentaram os melhores resultados com relação ao desenvolvimento do sistema radicular, mensurado pelo comprimento e peso seco das raízes. O comprimento do sistema radicular dos tratamentos estacas lenhosas com três e uma gema não apresentaram diferenças significativas entre si, o que ocorreu entre o tratamento estacas lenhosas com três gemas e os demais tratamentos. O peso seco das raízes das estacas lenhosas com três gemas foi de $972,50 \mathrm{mg}$, o qual não diferiu significativamente do peso das estacas com menor comprimento $(9 \mathrm{~cm})$ e apenas uma gema. Pelos resultados obtidos, pode-se concluir o seguinte:

1) Em condições de viveiro convencional com irrigação por microaspersão, a utilização de estacas lenhosas com três gemas ( $25 \mathrm{~cm}$ de comprimento) do porta-enxerto IAC 572 proporciona maior enraizamento e brotação das estacas e melhor desenvolvimento da parte aérea e do sistema radicular, resultando em mudas mais vigorosas, em condições de serem levadas ao campo 60 dias após o plantio.

2) As estacas lenhosas com uma gema e $9 \mathrm{~cm}$ de comprimento apresentaram porcentuais de enraizamento e brotação de $88 \%$ e $92 \%$, respectivamente, não diferindo daqueles obtidos para estacas lenhosas com três gemas, o que indica a viabilidade de utilização deste tipo de estaca que proporciona maior produtividade do material vegetativo das matrizes certificadas.

3) O estágio de maturação influenciou o enraizamento e brotação das estacas com diferenças significativas entre estacas lenhosas e herbáceas. No entanto, o número de gemas da estaca não teve efeito sobre o enraizamento, não sendo observadas diferenças entre estacas com uma, duas e três gemas em estacas lenhosas e uma e duas gemas em estacas herbáceas.

\section{REFERÊNCIASBIBLIOGRÁFICAS}

AlbuQUerque, J. A. S; AlbuQuerque, T. C. S. Método para enraizamento de estacas de videira na região do Submédio São Francisco. Petrolina, PE : EMBRAPA CPATSA, 1981. 8p. (EMBRAPA. CPATSA. Circular Técnica, 2).

ALVARENGA, L. R; FORTES, J. M. Enraizamento e desenvolvimento aéreo de alguns porta-enxertos de videira no município de Viçosa. In: CONGRESSO BRASILEIRO DE FRUTICUlTURA, 3., 1975, Rio de Janeiro. Anais... Campinas : SBF, 1976. V.2, p.591-595.

HARTMANN, H. T; KeSter, D. E. Plant propagation: principles and practices. Englewood Cliffs, N.J. : PrenticeHall, 1968.

MELO, N. F. de et al. Influência do AIB (ácido indolbutírico) e do tipo de estacas sobre o enraizamento do porta-enxerto de videira IAC 572. In: CONGRESSO NACIONAL DE BOTÂNICA, 47., 1996, Nova Friburgo. Resumos... Nova Friburgo : SBB, 1996. p. 440 .

Ciência Rural, v. 33, n. 1, jan-fev, 2003. 
TENNANT, D. A test of modified line intersect method estimating root lenght. Journal of Ecology. Oxford, v. 63, p.995-1001, 1975.

TERRA, M. M. et al. Influência da época de plantio e de substratos no enraizamento de estacas de porta-enxertos de videiras. In: SIMPÓSIO LATINO AMERICANO DE ENOLOGIA E VITICULTURA, 2.; JORNADA LATINO-
AMERICANA DE VITICULTURA E ENOLOGIA, 2. e SIMPÓSIO ANUAL DE VITICULTURA, 2, 1987, Garibaldi. Anais... Bento Gonçalves : Associação Brasileira dos Técnicos em Viticultura e Enologia, 1988. p.291295.

WINKLER, A. J. et al. General viticulture. Berkeley : University of California, 1974. 710p. il. 